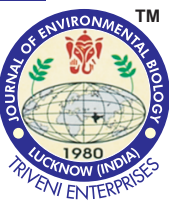

\title{
Profiling of major biochemical compounds for identification of nutritionally rich genotypes in mango
}

\begin{tabular}{lll}
\hline Paper received: 24.01.2018 Revised received: 14.05 .2018 & Re-revised received: $05.06 .2018 \quad$ Accepted: 30.07 .2018
\end{tabular}

\section{Authors Info \\ B.M. Muralidhara ${ }^{1 *}$, G.L. Veena', S. Rajan', A.K. Bhattacharjee ${ }^{3}$ and U. Hudedamani ${ }^{1}$ \\ 'Division of Crop Improvement and Biotechnology, ICAR- Central Institute for Subtropical Horticulture, Lucknow-226 101, India \\ ${ }^{2}$ ICAR- Central Institute for Subtropical Horticulture, Lucknow-226 101, India \\ ${ }^{3}$ Division of Post Harvest Management, ICAR-Central Institute for Subtropical Horticulture, Lucknow-226 101, India}

\section{*Corresponding Author Email :} muralidhara.bm@gmail.com

\section{Edited by \\ Dr. Sumati Gaumat}

\section{Reviewed by}

Dr. Laxuman Sharma

Dr. Manish Mishra

\section{Abstract}

Aim : Mango is a major fruit crop grown in India with wide variability for fruit colour, size, shape and fruit quality. The main objective of this study was profiling of mango genotypes and their genetic estimates for major biochemical compounds to identify superior genotypes as parents for developing nutritionally rich hybrids in future.

Methodology : Fifty mango varieties were analysed for biochemical compounds such as total antioxidants, total phenols, total flavonoids and total carotenoids. The $L^{*}, a^{*}, b^{*}$ values were recorded for pulp colour, and genetic estimates were also worked for genetic parameters such as genotypic variance, phenotypic variance, GCV, PCV, heritability and genetic advance. Correlation matrix for major biochemical compounds and $L^{*}, a^{*}, b^{*}$ values were also calculated.

Results : The present study revealed the presence of wide genetic variability in mango gene pool for

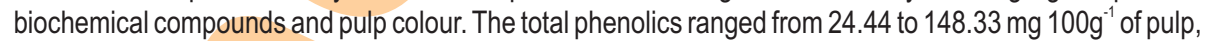

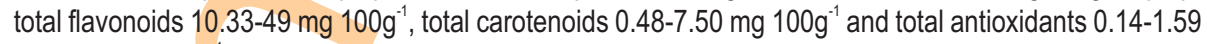
$\mu \mathrm{mol}$ Trolox $100 \mathrm{~g}^{-1}$ of pulp. The future genetic estimates showed that the phenotypic coefficient of variation (PCV) for all the characters was slightly higher than genotypic coefficient of variation (GCV), indicating the presence of environmental influence to some degree in the phenotypic expression of characters. However, the difference between PCV and GCV for all the traits was narrow suggesting that the traits were less influenced by environment. The broad sense heritability $\left(\mathrm{H}_{\mathrm{b}}^{2}\right)$ for all the compounds was high which indicates the phenotype of that trait strongly reflects its genotype.

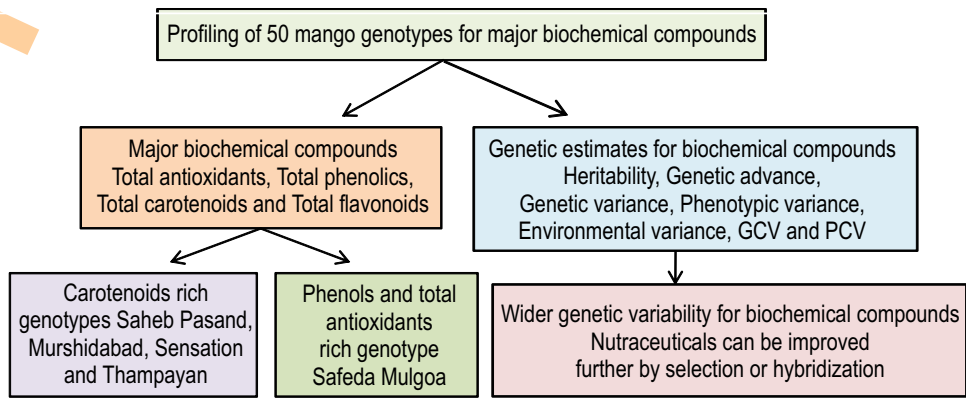

Interpretation : High values of PCV, GCV and heritability for total antioxidants, total phenols, total flavonoids and total carotenoids indicated high genetic variability and better scope for selection and improvement through hybridization.

Key words: Biochemical compounds, Genetic advance, Heritability, Mangifera indica, Superior parents

How to cite: Muralidhara, B.M., G.L. Veena, S. Rajan, A.K. Bhattacharjee and U. Hudedamani: Profiling of major biochemical compounds for identification of nutritionally rich genotypes in mango. J. Environ. Biol., 40, 177-182 (2019). 


\section{Introduction}

Mango (Mangifera indica L.) is one of the major fruit crop in the world and native to India. The wide genetic diversity of mango available in India is very rich, and presently more than one thousand vegetatively propagated varieties exist in our country. Previously, characterization of mango germplasm was mainly based on morphological traits (Ram and Rajan, 2003) and the main objectives of hybridization are to develop varieties which are high yielding, attractive colour, less fibre and resistance to pest and diseases. But, now priorities have changed and people are more conscious about health due to frequent occurrence of deadly diseases like cancer, heart attack and obesity problems. Recent developments in epidemiological studies have indicated that frequent consumption of natural antioxidants is associated with lower risk of cardiovascular disease and cancer (Renaud et al., 1998; Temple, 2000). Hence, currently there is a lot of demand for nutritionally rich genotypes due to its health benefits.

Mango is also well known for its good source of dietary antioxidants such as carotenoids and phenolic compounds. There is a necessity to combine production efficiency traits with improved fruit quality, including the new concept of improved fruit sensorial, nutritional and biochemical compounds (Wang and Lewers, 2007; Cheng et al., 2004). Correlation studies will also help in finding out the degree of inter relationship among various biochemical characters, which will further help in selection criteria for improvement. In consequence, present breeding programmes in fruits and vegetables are focused more on improvement of bioactive compounds (Diamanti et al., 2010). Improvement in quality of fruits can be achieved by selecting of genotype with increased content of bioactive compounds or by developing new hybrids. It has already been proved that wide variability exists for fruit physical parameters like weight, length, breadth, colour, size and shape, fruit quality (Majumder et al., 2012; Bhowmick and Banik, 2008) and chemical and nutritional traits such as TSS, sugar, acidity, phenols, carotenes and ascorbic acid content among different varieties (Himabindu et al., 2016).

Therefore, there is an urgent need for screening of mango gene pool for nutritional components to identify superior parents to develop nutritionally rich hybrids in future. In this context, the present study was carried out to see the genetic variability in different genotypes of mango for important biochemical compounds such as total antioxidants, total phenolics, total flavonoids and total carotenoids. This study provides information related to nutritional status of different cultivars for the identification of superior parents and genetic estimates for developing nutritionally rich hybrids in future.

\section{Materials and Methods}

Fifty mango genotypes viz., Angoordana, Chausa, Rajawala, Merkeara, Thampayan, Hushnara, Kasi Ratnalu, Jawahar, Lal Mani, Surkha Thakurbag, Menaka, Allahabadi Chausa, Serehayat, Eldon, Neeleshwari, NR-122, Kunjlata,
Amin, Samar Bahist Rampur, Arka Aruna, Mithuwa, Khader, Brindabani, Bathuie Katikee, Rataul, Gulabi, Chandrakaran, Nekkare, Vellaikolumban, Safeda Mulgoa, Neelgoa, Saheb Pasand, Konkan Ruchi, Murshidabad, Santra, Chilta Khas, Mylepelian, Rumani, Bhogal Shah, Janardan Pasand, Kalapahar, Sadaphal, Ratna, Benazir, Gootee, MadhavaRao Pasand, EC95862, PFN-11, Manjeera and Sensation were used for the study. The fully matured fruits were randomly collected from mango orchards located at institute farm at Rehmankhera, Lucknow, India. The fruits were washed with water to remove field heat, as well as dirt deposited on fruits. The fruits were stored at room temperature for uniform ripening by considering softness and colour. The pulp of mango genotypes was used for analysis of different biochemical compounds, such as total antioxidants, total phenols, total flavonoids and total carotenoids. The colour reading was recorded immediately after cutting the fruits.

Estimation of biochemical compounds: Total phenolics content in the extracts were estimated by the Folin-Ciocalteau reagent method (Singleton et al., 1999). The absorbance was recorded at $750 \mathrm{~nm}$ by using a UV-VIS spectrophotometer. Gallic acid was used as standard and total phenolic content was determined on the basis of calibration equations, expressed as gallic acid equivalents (GAE) in mg per $100 \mathrm{~g}$ of pulp. The analysis of total flavonoid content was determined according to the colorimetric method (Dewanto et al., 2002). The absorbance was recorded at $510 \mathrm{~nm}$ against a reagent blank. The results were expressed as mg quercetin equivalents per $100 \mathrm{~g}$ fresh weight. Total carotenoid content was determined following the modified method of Ranganna (1997) using acetone and petroleum ether as extracting solvents and measured the absorbance at 452 $\mathrm{nm}$. The results were expressed as mg per $100 \mathrm{~g}$ of pulp. The total antioxidant activity of fruits was determined by using CUPRAC (Cupric Reducing Antioxidant Capacity) assay (Apak et al., 2004). The absorbance was recorded at $450 \mathrm{~nm}$ against a reagent blank in the UV-VIS spectrophotometer. The units were expressed in trolox -Trolox per $100 \mathrm{~g}$ pulp.

Colour parameters : Pulp colour was determined longitudinally at three equidistant points on freshly cut fruits by using ColorLite Sph 850 spectrophotometer (ColorLite $\mathrm{GmbH}$, KatlenburgLindau, Germany), In $L^{*}, a^{*}, b^{*}$ scale, whereas $L^{*}$ is the measure of lightness, the positive values of $a^{*}$ are in direction of redness and positive values of $b^{*}$ are the vector of yellowness. The negative values of $a^{*}$ indicates colour towards greenness and that of $b^{*}$ depicts blueness. Each fruit pulp was measured at three different places and mean values were obtained.

Experimental design and genotypic analysis : Data were expressed as means standard deviation of three replications. ANOVA (SPSS version 16.0) and Turkey's post hoc test were used to determine the mean difference of different biochemical compounds, and $L^{*}, a^{*}, b^{*}$ values and Pearson's correlation test was used to determine the correlation. Genetic parameters were estimated as suggested by Johnson et al. (1955), Panse (1957) and Gomez and Gomez (1984). Heritability in broad sense $\left(\mathrm{H}_{\mathrm{b}}^{2}\right)$ 
and genetic advance were also calculated because these are the only useful measure of heritability for out crossing crops (Wricke and Weber, 1986). The genotypic and phenotypic coefficient of variation were calculated as per Burton and De Vane (1953), heritability by following the method of Johnson et al. (1955) and genetic advance by that of Allard (1960).

\section{Results and Discussion}

Fifty mango genotypes were evaluated for major biochemical compounds such as total phenols, total flavonoids, total carotenoids along with total antioxidants activity whereas colorlite values were recorded to show the pigmentation pattern in the pulp (Table 1). Among the genotypes, significant variability was observed from 0.14-1.59 $\mathrm{mmol}$ Trolox $100 \mathrm{~g}^{-1}$ for total antioxidants. The genotype Safeda Mulgoa (1.59 $\mu \mathrm{mol}$ Trolox $\left.100 \mathrm{~g}^{-1}\right)$ had higher antioxidants, followed by Nekkare $(1.33 \mu \mathrm{mo}$ Trolox $\left.100 \mathrm{~g}^{-1}\right)$ and minimum was in Rajawala $(0.14 \mu \mathrm{mol}$ Trolox $\left.100 \mathrm{~g}^{-1}\right)$. The genotype Safeda Mulgoa had ten times more total antioxidants compared to Rajawala which bears big sized fruits (1.0 to $2 \mathrm{~kg}$ per fruit) with irregular shape.

Total phenol contents were higher in genotype Safeda Mulgoa (148.33 mg 100 $\mathrm{g}^{-1}$ ) followed by Brindabani (137.50 mg $100 \mathrm{~g}^{-1}$ ) and lowest in Rajawala $\left(24.44 \mathrm{mg} 100 \mathrm{~g}^{-1}\right)$. Ribeiro et al. (2007) reported that Safeda Mulgoa had higher phenolics among the varieties but lower than the pulp of cultivar Uba (200 $\left.\mathrm{mg} 100 \mathrm{~g}^{-1}\right)$. Higher antioxidants and phenolics content in Safeda Mulgoa indicate that, the phenols contribute more to antioxidant activity compared to flavonoids and carotenoids. The results also indicate that total antioxidants have positive relationship with total phenol contents. The genotype Safeda Mulgoa had six times higher amount of phenolics compared to Rajawala. Kjersti et al. (2012) reported wider variability for phenols i.e., 57 to 133 mg per $100 \mathrm{~g}$ of fruit weight. in 27 genotypes of strawberry, which was lower than the Safeda Mulgoa.

Similar to phenols the highly significant differences were found for total flavonoids content which varied from 10.33-49.00 $\mathrm{mg} 100 \mathrm{~g}^{-1}$ among different genotypes. The polyembryonic genotype Nekkare had highest total flavonoids content $(49.0 \mathrm{mg}$ $100 \mathrm{~g}^{-1}$ ) followed by Santra $\left(34.0 \mathrm{mg} 100 \mathrm{~g}^{-1}\right)$, while lowest was found in genotype NR-122 (10.3 mg 100g $\left.{ }^{-1}\right)$. Monaco et al. (2014) reported high amount of total flavonoids content $(14.16 \mathrm{mg}$ mangiferin per $100 \mathrm{~g}$ ) in the pulp of Palmer variety, which was almost 3-4 times lower than genotype Nekkare.

Mango is one of the fruits having high amount of carotenoids and more than 70 per cent of $\beta$-carotene. Carotenoids contain $\alpha$-carotene, $\beta$-carotene and lycopene, and among them $\beta$-carotene is the most prevalent one. A wide range

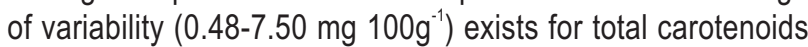
among genotypes. The genotype Saheb Pasand possessed high amount of total carotenoids $\left(7.50 \mathrm{mg}^{100 \mathrm{~g}^{-1}}\right)$ followed by

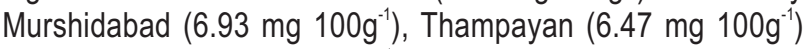

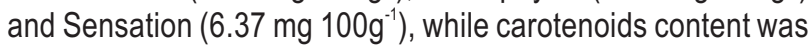

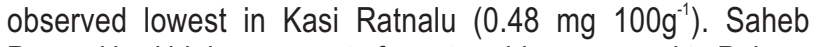
Pasand had higher amount of carotenoids compared to Palmer

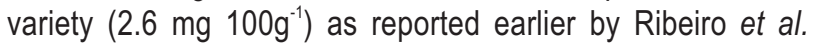
(2007) and five times (1.2 mg per $100 \mathrm{~g}$ ) higher than papaya (Yahia et al., 2009). The results clearly indicate that a wide range of variability exists for biochemical compounds in mango gene pool and it varies from genotype to genotype. Hence, it is important to study them in all the commercial and noncommercial varieties for identification of superior parents. The morphological and molecular diversity was worked for East and North Indian heirloom varieties of mango (Anju Bajpai, 2015; Srivastava, et al., 2012).

The $L^{*}, a^{*}, b^{*}$ values were recorded for pulp of all the genotypes by using ColorLlite Sph 850 spectrophotometer and values are represented in Table.1. The $L^{*}$ values indicated lightness of the pulp where it varied from 36.41 to 66.11 and $a^{*}$ values varied from negative to positive (-0.5 to 21.74). But all the $b^{*}$ values were positive and ranged from 19.76 to 56.10 . It indicated the dominance of yellowness in pulp colour over the redness. Highest $a^{*}$ value (21.74) was found in the genotype sensation, followed by Saheb Pasand (21.54) and Chandrakaran (20.45). The $b^{*}$ values were found highest in genotype Chandrakaran (56.11) followed by Rataul (54.44) and Murshidabad (53.31). The results indicated that total carotenoids have positive relationship with $a^{*}$ and $b^{*}$ values. Ribeiro et al. (2007) have also reported that positive values of $a^{*}$ and $b^{*}$ are attributed to the carotenoids present in the mango pulp.

The knowledge of genetic characters such as heritability, PCV, GCV among the traits under selection is very useful for assessing the genetic progress in breeding programme and developing effective breeding strategies (Falconer and Mackay, 1996). The estimates of genetic parameters for biochemical compounds were worked out and are presented in Table 2 . The knowledge of genetic variation among different fruit characters and their heritability is most important in highly out crossing species like mango (Rajan et al., 2009).

In the present study, genetic estimates for biochemical compounds revealed the magnitude of phenotypic variance, and phenotypic co-efficient of variance (PCV) was higher than the genotypic variance and genotypic co-efficient of variance (GCV) for all the characters indicating the presence of environmental effect on expression of traits. However, the difference between PCV and GCV for all the traits was narrow meaning that the traits were less influenced by environment. The high values of PCV and GCV recorded for total antioxidants, phenols, flavonoids and carotenoids indicated the presence of high genetic variability and better scope for selection and improvement. Similar results were observed for morphological traits such as fruit weight (20.84), fruit length (11.57), fruit peel (19.61) by Bhowmick and Banik (2008) and for bio-chemical components such as ascorbic acid (40.55), $\beta$ carotene (27.59) and total phenols (45.98) by Himabindu et al. (2016) in mango for PCV. 
Table 1 : Variability in mango genotypes for major biochemical compounds and colour characteristics

\begin{tabular}{|c|c|c|c|c|c|c|c|}
\hline Genotypes & $\begin{array}{l}\text { Total antioxidants } \\
\left(\mu \mathrm{mol} \text { Trolox } 100 \mathrm{~g}^{-1}\right)\end{array}$ & 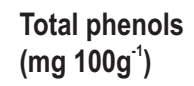 & $\begin{array}{l}\text { Total flavonoids } \\
\left.\text { (mg 100 } \mathrm{g}^{-1}\right)\end{array}$ & 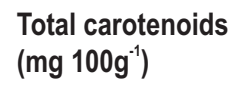 & $L^{*}$ & $a^{*}$ & $\mathbf{b}^{*}$ \\
\hline Angoordana & 0.69 & 76.94 & 19.00 & 4.30 & 44.08 & 7.88 & 35.24 \\
\hline Chausa & 0.54 & 52.92 & 17.00 & 1.03 & 57.25 & 7.04 & 41.15 \\
\hline Rajawala & 0.14 & 24.44 & 14.00 & 2.50 & 54.58 & 10.28 & 43.37 \\
\hline Merkeara & 0.44 & 43.19 & 12.67 & 0.91 & 51.76 & -0.03 & 19.76 \\
\hline Thampayan & 0.37 & 30.69 & 15.00 & 6.47 & 47.54 & 13.89 & 37.60 \\
\hline Hushnara & 0.73 & 65.97 & 32.33 & 0.85 & 45.02 & 2.82 & 25.94 \\
\hline Kasi Ratnalu & 0.68 & 70.56 & 14.67 & 0.48 & 66.11 & -0.06 & 12.56 \\
\hline Jawahar & 0.42 & 44.03 & 19.00 & 2.99 & 60.69 & 10.76 & 42.47 \\
\hline Lal Mani & 0.66 & 88.61 & 19.00 & 2.25 & 54.18 & 10.43 & 46.54 \\
\hline Surkha Thakurbag & 0.39 & 42.78 & 18.33 & 5.66 & 56.69 & 10.99 & 49.96 \\
\hline Menaka & 0.26 & 37.92 & 12.67 & 1.21 & 54.60 & 6.48 & 38.02 \\
\hline Allahabadi Chausa & 0.35 & 34.72 & 24.00 & 3.80 & 52.78 & 16.36 & 52.48 \\
\hline Serehayat & 0.55 & 74.31 & 18.67 & 1.41 & 58.65 & 7.05 & 43.86 \\
\hline Eldon & 0.44 & 52.92 & 15.33 & 3.53 & 52.91 & 14.36 & 45.74 \\
\hline Neeleshwari & 0.98 & 99.03 & 22.00 & 3.77 & 59.94 & 10.34 & 48.14 \\
\hline NR-122 & 0.22 & 24.72 & 10.33 & 0.79 & 57.79 & 1.90 & 25.32 \\
\hline Kunjlata & 0.29 & 39.44 & 12.67 & 1.45 & 55.96 & 9.26 & 47.71 \\
\hline Amin & 0.22 & 35.97 & 13.00 & 0.86 & 53.51 & 17.43 & 49.17 \\
\hline Samar Bahist Rampur & 0.45 & 38.19 & 18.67 & 2.74 & 54.33 & 9.18 & 41.28 \\
\hline Arka Aruna & 0.24 & 30.69 & 17.00 & 0.88 & 51.47 & 5.62 & 37.90 \\
\hline Mithuwa & 0.51 & 54.03 & 33.00 & 3.50 & 41.29 & 11.02 & 32.46 \\
\hline Khader & 0.85 & 78.06 & 20.00 & 1.83 & 55.89 & 9.00 & 36.29 \\
\hline Brindabani & 0.45 & 137.50 & 15.67 & 2.91 & 59.59 & 14.97 & 44.49 \\
\hline Bathuie Katikee & 0.67 & 60.00 & 32.00 & 3.32 & 45.92 & 17.43 & 39.52 \\
\hline Rataul & 0.62 & 65.14 & 25.33 & 4.55 & 55.44 & 19.45 & 54.44 \\
\hline Gulabi & 0.28 & 33.47 & 13.00 & 2.54 & 54.28 & 3.30 & 37.18 \\
\hline Chandrakaran & 1.09 & 103.06 & 49.00 & 5.01 & 58.78 & 20.45 & 56.11 \\
\hline Nekkare & 1.33 & 108.61 & 23.33 & 2.13 & 42.05 & 15.84 & 45.15 \\
\hline Vellaikolumban & 0.73 & 61.67 & 23.67 & 1.98 & 44.24 & 11.92 & 37.85 \\
\hline Safeda Mulgoa & 1.59 & 148.33 & 21.00 & 2.41 & 54.41 & 3.99 & 40.09 \\
\hline Neelgoa & 0.51 & 36.11 & 18.67 & 1.55 & 48.00 & 10.22 & 30.34 \\
\hline Saheb Pasand & 0.56 & 56.25 & 22.67 & 7.50 & 52.62 & 21.54 & 49.16 \\
\hline Konkan Ruchi & 0.73 & 75.56 & 13.33 & 2.64 & 36.42 & 10.31 & 37.99 \\
\hline Murshidabad & 0.56 & 55.97 & 19.67 & 6.93 & 54.52 & 16.15 & 53.31 \\
\hline Santra & 0.76 & 61.39 & 34.00 & 5.00 & 48.10 & 18.69 & 41.17 \\
\hline Chilta Khas & 0.35 & 35.28 & 24.33 & 2.71 & 38.08 & 9.64 & 34.32 \\
\hline Mylepelian & 0.44 & 39.44 & 20.33 & 3.05 & 51.76 & 8.05 & 45.68 \\
\hline Rumani & 0.34 & 27.78 & 14.33 & 1.58 & 59.72 & 6.58 & 34.63 \\
\hline Bhogal Shah & 0.63 & 44.03 & 19.00 & 2.77 & 45.84 & 14.71 & 40.50 \\
\hline Janardan Pasand & 0.72 & 59.03 & 20.33 & 1.11 & 58.38 & 2.82 & 32.97 \\
\hline Kalapahar & 0.37 & 35.69 & 18.33 & 1.36 & 43.14 & 7.90 & 38.32 \\
\hline Sadaphal & 0.66 & 49.86 & 20.00 & 2.36 & 50.68 & 8.89 & 41.14 \\
\hline Ratna & 0.85 & 79.03 & 29.67 & 3.43 & 57.12 & 13.30 & 49.01 \\
\hline Benazir & 0.74 & 61.67 & 30.67 & 3.87 & 44.74 & 12.77 & 39.38 \\
\hline Gootee & 0.53 & 38.61 & 21.00 & 3.63 & 42.37 & 17.00 & 43.52 \\
\hline MadhavaRao Pasand & 0.27 & 22.64 & 19.00 & 3.80 & 41.19 & 15.31 & 38.04 \\
\hline EC-95862 & 0.74 & 70.83 & 26.67 & 4.43 & 46.29 & 16.95 & 37.26 \\
\hline PFN-11 & 0.36 & 52.22 & 15.00 & 1.45 & 49.61 & 5.50 & 32.14 \\
\hline Manjeera & 0.30 & 35.69 & 11.33 & 1.15 & 58.36 & 4.58 & 35.69 \\
\hline Sensation & 0.41 & 54.31 & 23.00 & 6.37 & 49.20 & 21.74 & 38.78 \\
\hline CD@5\% & 0.08 & 12.40 & 4.01 & 0.50 & 11.98 & 3.70 & 11.48 \\
\hline CV $(\%)$ & 6.964 & 9.986 & 9.148 & 8.12 & 10.84 & 15.93 & 13.38 \\
\hline
\end{tabular}

All the values shown here are average of 3 replicates for each genotype and each biochemical compounds and colour parameter 
Table 2 : Estimates of genetic parameters for biochemical compounds in mango genotypes

\begin{tabular}{lllll}
\hline Genetic parameters & Total antioxidants & Total phenolics & Total flavonoids & Total carotenoids \\
\hline F-Value & 155.46 & 70.35 & 44.46 & 162.70 \\
Mean & 0.56 & 56.99 & 20.45 & 2.90 \\
Range Minimum & 0.14 & 22.64 & 10.33 & 0.48 \\
Maximum & 0.59 & 148.33 & 49 & 7.5 \\
CV $(\%)$ & 6.964 & 9.986 & 9.148 & 8.12 \\
$\sigma^{2} g$ & 0.078 & 730.193 & 50.812 & 2.970 \\
$\sigma^{2} \mathrm{e}$ & 0.002 & 31.588 & 3.508 & 0.055 \\
$\sigma^{2} p$ & 0.080 & 761.781 & 54.319 & 3.025 \\
PCV & 50.285 & 48.434 & 36.034 & 60.054 \\
GCV & 49.803 & 47.419 & 34.851 & 59.505 \\
$H_{b}^{2}$ & 98.095 & 54.853 & 93.543 & 98.179 \\
GA & 0.570 & 95.636 & 14.202 & 3.518 \\
GAM $(\%)$ & 101.612 & 69.437 & 121.458 \\
\hline
\end{tabular}

$\mathrm{GA}=$ Genetic advance, $\mathrm{H}_{\mathrm{b}}^{2}=$ Heritability in broad sense; $\sigma^{2} \mathrm{~g}=$ genotypic variance; $\sigma^{2} \mathrm{e}=$ environment variance; $\sigma^{2} \mathrm{p}=$ Phenotypic variance; $\mathrm{CV}=$ coefficient of variability

Table 3 : Correlation coefficients for biochemical compounds and colour value of mango genotypes

\begin{tabular}{|c|c|c|c|c|c|c|c|}
\hline & Total antioxidants & Total phenols & Total flavonoids & Total carotenoids & $L^{*}$ & $a^{*}$ & $b^{*}$ \\
\hline Total antioxidants & 1.00 & & & & & & \\
\hline Total phenols & 0.82 & 1.00 & & & & & \\
\hline Total flavonoids & 0.53 & 0.35 & 1.00 & & & & \\
\hline Total carotenoids & 0.12 & 0.09 & 0.40 & 1.00 & & & \\
\hline$L^{*}$ & -0.06 & 0.13 & -0.23 & -0.16 & 1.00 & & \\
\hline$a^{*}$ & 0.12 & 0.12 & 0.49 & 0.73 & -0.26 & 1.00 & \\
\hline$b^{*}$ & 0.12 & 0.19 & 0.28 & 0.52 & 0.11 & 0.68 & 1.00 \\
\hline
\end{tabular}

GCV alone is not sufficient to estimate the extent of heritable variability in population. Therefore estimation of heritability is also important. Heritability estimates were high for all the traits which indicated the phenotype of that trait strongly reflects its genotype. The heritable values ranged from 93.54 to 98.17 among the biochemical compounds. Himabindu et al. (2016) and Gill and Navprem (2015) have also reported similar results for heritability in mango for morphological and biochemical characters such as fruit weight (96.31), fruit length (93.19), pulp weight (98.6) ascorbic acid (97.75), $\beta$-carotene (90.96) and total phenols (98.86). According to Jonshon et al. (1955), an estimated heritability associated with genetic advance is more reliable compared to heritability alone for prognosticating the impact of selection. High heritability accompanied by high genetic advance is mainly referred to the action of additive genes (Panse, 1957). So it can be concluded that different biochemical compounds components under the study can be improved though selection and hybridization.

The correlation coefficients among biochemical compounds and $L^{*}, a^{*}, b^{*}$ values studied among different genotypes are presented in Table 3 . The results revealed that the total antioxidants had significant positive correlation with total phenols content (0.82) and total flavonoids (0.53). Total flavonoids showed higher positive correlation values with total carotenoids $(0.40)$, however total carotenoids content were highly dependent on $a^{*}(0.73)$ and $b^{*}(0.52)$ values. Existence of highly positive relationship between the total phenolics content and antioxidant activity has been reported in several plant species (Chen and Yen, 2007). The $a^{*}$ values also showed positive correlation with $b^{*}$ values. The results clearly indicated that yellowness and redness of fruit is due to higher carotenoids content. If $a^{*}$ and $b^{*}$ values are higher, the carotenoids content will be more. The study concludes that wider genetic variability for biochemical compounds was found among genotypes. The genotypes Saheb Pasand, Murshidabad, Sensation and Thampayan were identified as rich source of carotenoids and Safeda Mulgoa as a good source of phenols and total antioxidants. This information will be helpful in identifying superior parents for developing nutritionally rich hybrids in future.

\section{Acknowledgments}

Authors are thankful to the Director ICAR-Central Institute of Subtropical Horticulture, Lucknow for providing facilities and guidance during the study. We acknowledge the technical staff of Division of Crop Improvement and Biotechnology for their assistance in sample collection. 


\section{References}

Allard, R.W.: Principles of Plant Breeding. John Willey Inc., London UK (1960)

Bajpai, A., M. Muthukumar, Israr Ahmad, K.V. Ravishankar, V.A. Parthasarthy, Bhuwon Sthapit, Ramanatha Rao, J.P.Verma and S. Rajan: Molecular and morphological diversity in locally grown noncommercial (heirloom) mango varieties of North India. J. Environ. Biol., 37, 221-228 (2015).

Apak, R., K. Guclu, M. Ozyurek and S.E. Karademir: Novel total antioxidant capacity index for dietary polyphenols and vitamin $\mathrm{C}$ and $\mathrm{E}$, using their cupric ion reducing capability in the presence of neocuprine: CUPRAC method. J. Agric. Food Chem., 52, 7970-81 (2004).

Bhowmick, N. and B.C. Banik: Genetic variability and correlation studies for fruit physico-chemical properties of some mango cultivars grown under new alluvial zone of West Bengal. Asian J. Hort., 3 , 346-349 (2008).

Burton, G.W. and F.H. De Vane: Estimating heritability in tall fescue (Festuea arundianacea) from replicated clonal material. Agron. J., 45, 478-481 (1953)

Chen, H.Y. and G.C. Yen: Antioxidant activity and free radical scavenging capacity of extracts from guava (Psidium guajava L.) leaves. Food Chem., 101, 686-694 (2007)

Cheng, C.H., A.G. Seal, H.L. Boldingh, K.B. Marsh, E.A. Mac Rae, S.J. Murphy and A.R. Ferguson: Inheritance of taste characters and fruit size and number in a diploid Actinidia chinensis (kiwifruit) population. Euphytica, 138, 185-195(2004).

Dewanto, X.Z., A.K. Wu and R.H. Liu: Thermal processing enhances the nutritional value of tomatoes by increasing total antioxidant activity. J.Agric. Food Chem., 50, 10-14 (2002).

Diamanti, J., F. Capocasa, M. Battino and B. Mezzetti: Evaluation of F. x ananassa intra-specific and inter-specific back-crosses to generate new genetic material with increased fruit nutritional quality. J. Berry Res., 1, 1-12 (2010).

Falconer, D.S. and T.F.C. Mackay: Introduction to Quantitative Genetics. $4^{\text {th }}$ Edn., Longman, Essex, UK (1996).

Gomez, K.A. and A.A. Gomez: Statistical procedures for Agricultural Research. John Wiley and Sons. Inc., New York (1984).

Gill, M. S. and S. Navprem: Genetic parameters, character association and path analysis for fruit yield and its component characters in mango (Mangifera indica L.). Indian. J. Plant Genet. Res., 28, 292295 (2015).

Himabindu, A., D. Srihari, M. Rajasekhar, V. Sudhavani, P. Subbarammamma and K. Uma Krishna: Genetic variability and heritability studies of mango cultivars. Int. J. Sci. Nat., 7, 168-172 (2016).
Johnson, H.W., H.F. Robinson and R.E. Comstock: Estimation of genetic and environmental variability in soybean. Agron. J., 47, 314-318 (1955).

Kjersti, A., M. Sebastian, N. Arnfinn and S. Grete: Phenolic compounds in strawberry (Fragaria $x$ ananassa Duch.) fruits: Composition in 27 cultivars and changes during ripening. Food Chem., 132, 86-97 (2012).

Majumder, D.A.N., L. Hassan, M.A. Rahim and M.M. Kabir: Genotypic and phenotypic variability in mango (Mangifera indica L.). Bangladesh J. Agril. Res., 37, 683-690 (2012).

Monaco, K.A., S.M. Costa, M.R. Uliana and G.P.P. Lima: Sanitizers effect in mango pulp and peel antioxidant compounds. Food Nutr. Sci., $\mathbf{5}$, 929-935 (2014).

Panse, V.G.: Genetics of quantitative characters in relations to plant breeding. Indian. J. Genet., 17, 318-329 (1957).

Rajan, S., L.P. Yadava, R. Kumar and S.K. Saxena: Genetic divergence in mango varieties and possible use in breeding. Indian. J. Hort., 66, 7-12 (2009).

Ram, S. and S. Rajan: Status report on genetic resources of mango in Asia-Pacific region. IPGRI office for South Asia, New Delhi, India, pp. 64-68 (2003).

Ranganna, S.: In manual of analysis of fruit and vegetable products. $9^{\text {th }}$ Edn., Tata Mc Graw Hill, New Delhi (1997).

Renaud, S.C., R. Gueguen, J. Schenker and A. Houtaud: Alcohol and mortality in middle-aged men from eastern France. Epidemiology, 9,184-188 (1998).

Ribeiro, S.M.R., J.H. Queiroz, Queiroz Melr, F.M. Campos and H.M.P. Sant Ana: Antioxidant in mango (Mangifera indica L.) pulp. Pl. Foods Human Nutr., 62, 13-17 (2007).

Singleton, V.L., R. Orthofer and R.M. Lamuela-Raventos: Analysis of total phenols, other oxidation substrates and antioxidants by means of Folin-Ciocalteu reagent. Methods Enzymol., 299, 152178 (1999).

Srivastava, N., A. Bajpai, R. Chandra, S. Rajan, M. Muthukumar and M.K. Srivastava: Comparison of PCR based marker systems for genetic analysis of mango. J. Environ. Boil., 33, 159-166 (2012).

Temple, N.J.: Antioxidants and disease: More questions than answers. Nutr. Res., 20, 449-459 (2000).

Wang, S.Y. and K.S. Lewers: Antioxidant capacity and flavonoid content in wild strawberries. J. Am. Soc. Hortic. Sci., 132, 629-637 (2007).

Wricke, G. and W.E. Weber: Quantitative genetics and selection in plant breeding. Walter de Gruyter \& Co., Berlin, Germany (1986).

Yahia, E.M., G.K. Ramirez-Padilla and A. Carrillo-Lopez: Carotenoid content of five fruits and vegetables and their bioconversion to vitamin a measured by retinol accumulation in rat livers. Acta Hortic., 841, 619-624 (2009). 